\title{
Electrochemical Behaviour of Chlorine on Platinum Microdisk and Screen Printed Electrodes in a Room Temperature Ionic Liquid
}

Krishnan Murugappan, Damien W. M. Arrigan, Debbie S. Silvester*

Nanochemistry Research Institute, Department of Chemistry, Curtin University, GPO Box U1987, Perth, 6845, Australia.*Email:d.silvester-dean@curtin.edu.au, Phone:

$+61(8) 92667148$

Submitted to: the Journal of Physical Chemistry C. 


\title{
Electrochemical Behaviour of Chlorine on Platinum Microdisk and Screen Printed Electrodes in a Room Temperature Ionic Liquid
}

\begin{abstract}
As a result of the toxic and corrosive nature of chlorine gas, simple methods for its detection are required for monitoring and control purposes. In this paper, the electrochemical behaviour of chlorine on platinum working electrodes in the room temperature ionic liquid (RTIL) 1-ethyl-3-methylimidazolium bis(trifluoromethylsulfonyl)imide $\left(\left[\mathrm{C}_{2} \mathrm{mim}\right]\left[\mathrm{NTf}_{2}\right]\right)$ is reported, as a basis for simple sensor devices. Cyclic voltammetry (CV) and chronoamperometry $(\mathrm{CA})$ on a $\mathrm{Pt}$ microelectrode revealed the two electron reduction of $\mathrm{Cl}_{2}$ to chloride ions. On the $\mathrm{CV}$ reverse sweep, an oxidation peak due to the oxidation of chloride was observed. The reduction process was diffusion controlled at the concentrations studied ( $\leq 4.5 \%$ in the gas phase), in contrast to a previous report (J. Phys. Chem. C, 2008, 112, 19477), which examined only $100 \%$ chlorine. The diffusion-controlled currents were linear with gas phase concentration. Fitting of the CA transients to the Shoup and Szabo expression gave a diffusion coefficient for chlorine in the RTIL of ca. $2.6 \times 10^{-10} \mathrm{~m}^{2} \mathrm{~s}^{-1}$. Furthermore, determination of the equilibrium concentration of $\mathrm{Cl}_{2}$ in the RTIL phase as a function of gas phase concentration enabled a value of 35 to be determined for the Henry's law dimensionless volatility constant. The electrochemical behaviour of chlorine on a Pt screenprinted electrode was also investigated, suggesting that these devices may be useful for chlorine detection in conjunction with suitable RTILs.
\end{abstract}

Keywords: Chlorine reduction - Room temperature ionic liquids • Cyclic Voltammetry • Henry’s Law Constant • Gas sensing • Reaction mechanism. 


\section{Introduction}

Chlorine is a diatomic yellowish green gas that is denser than air, has an intensely suffocating odour and is used in the production of other chlorine-containing compounds. Due to their very strong oxidising properties, chlorine compounds (such as sodium hypochlorite and chlorine dioxide) are used extensively throughout the world in water treatment, particularly in sewage treatment and in swimming pool disinfection. ${ }^{1,2}$ Chlorine is also used in the bleaching of cloth and paper, ${ }^{3}$ for the production of chlorinated organic solvents and polymers, and for applications in stabilization of packaged foods. ${ }^{4,5}$ Due to its toxicity, chlorine has been used as a chemical warfare agent, either alone or in a mixture such as mustard gas, for example in World War $\mathrm{I}^{1}$ and more recently in Syria. ${ }^{6}$

Chlorine's toxicity is due to its strong oxidising power. When chlorine is inhaled, it reacts with moisture in the mucosal surface and airways, forming $\mathrm{HCl}$ and $\mathrm{HClO}$ which causes tissue damage. ${ }^{2}$ Damage can also occur to the eyes and skin in the presence of moisture. The current (USA) Occupational Safety and Health Administration permissible exposure limit (OSHA PEL) is $1 \mathrm{ppm}$. At $30 \mathrm{ppm}$ and above, dyspnea and esophageal perforation might occur. Given its high toxicity and importance in the relevant industries, it is essential to be able to monitor and detect low concentrations of chlorine. One strategy to detect toxic gases is to use electrochemical sensors, an example of which is the amperometric gas sensor (AGS), where the current is monitored as a function of concentration. Companies such as Alphasense and Membrapor currently produce AGSs for the detection of chlorine gas.

Common aqueous electrolyte solutions currently employed in AGSs cannot withstand extreme conditions such as high temperature and pressure. ${ }^{7,8}$ By replacing the solvent/electrolyte with non-volatile solvents such as room temperature ionic liquids (RTILs), more robust sensors may be created. ${ }^{7}$ RTILs are composed entirely of ions, and possess 
intrinsic properties such as low volatility, high viscosity, wide electrochemical windows, tuneability and the ability to dissolve a wide range of species. ${ }^{9}$ Before employing RTILs in AGSs, the electrochemical behaviour of gases in RTILs must be explored, which is the focus of this work.

The electrochemical behaviour of chlorine in acetonitrile, a conventional aprotic solvent, has been studied by Sereno et al. ${ }^{10}$ and Huang et al. ${ }^{11}$ on Pt electrodes, who found that it underwent a two-electron, diffusion-controlled reduction (equation 1).

$$
\mathrm{Cl}_{2(\mathrm{~g})}+2 \mathrm{e}^{-} \rightleftharpoons 2 \mathrm{Cl}^{-}
$$

The electrochemical behaviour of chlorine on platinum electrodes in several RTILs that were equilibrated with $100 \%$ gaseous chlorine was studied by Huang et al. ${ }^{11}$ Cyclic voltammetry (CV) revealed a broad reduction wave followed by a sharp oxidation peak. The broad reduction wave was attributed to the two electron reduction of chlorine and the reverse peak to the oxidation of chloride. However the voltammetry was highly unusual; not only was hysteresis (cross-over of forward and reverse scans) observed, but the currents were observed to decrease with increasing scan rate. This behaviour is rarely observed experimentally and it was suggested through theoretical modelling to be the result of non-dissociative adsorption of chlorine on the Pt electrode surface, followed by electron transfer (equations 2 and 3 ).

$$
\begin{aligned}
& \mathrm{Cl}_{2 \text { (soln) }} \rightleftharpoons \mathrm{Cl}_{2 \text { (ads) }} \\
& \mathrm{Cl}_{2(\text { ads })}+2 \mathrm{e}^{-} \rightleftharpoons 2 \mathrm{Cl}^{-}
\end{aligned}
$$

In this mechanism, as chlorine gas is reduced at the electrode, the equilibrium in equation 2 becomes unbalanced, leading to net desorption of $\mathrm{Cl}_{2}$. This effectively "unblocks" the electrode, leaving more of the electrode surface available for electron transfer, and resulting 
in an increase in current over time. At lower scan rates (longer timescale), there is more desorption of $\mathrm{Cl}_{2}$ from the electrode surface, and hence higher currents are observed.

It is important to note here that in an AGS, the concentration in the gaseous phase is not the same as the concentration in the liquid phase. The concentration of gas molecules in the liquid phase differs from solvent to solvent and depends on the specific interactions of the gas molecules with the solvent. For a gas to be detected in an AGS, it must partition into the solvent and form an equilibrium $\left(K_{\mathrm{e}}\right)$ between the two phases (Fig. 1). Once equilibrium is established, the gas molecules are either reduced or oxidised on the electrode surface when a potential is applied, producing a current which is directly proportional to the concentration of gas in the liquid phase, and via $K_{\mathrm{e}}$, in the gas phase.

In this work, the focus is to explore the electrochemical behaviour of low gas-phase concentrations of chlorine (less than $4.5 \%$ in nitrogen) in RTILs on platinum microelectrodes, in order to determine if quantification of low concentrations of chlorine is possible, and to evaluate the translation of that electrochemical behaviour to screen printed electrodes (SPEs). The use of SPEs may lead to many advantages for a gas sensor, such as smaller volumes of electrolyte (thin layer), leading to faster response times, and cheaper manufacturing. Pt SPEs were examined for their viability in chlorine gas sensing to give a comparison of the behaviour of SPEs versus conventional electrodes in RTILs. 


\section{Experimental Section}

\subsection{Chemical Reagents}

1-ethyl-3-methylimidazolium bis(trifluoromethylsulfonyl)imide $\quad\left(\left[\mathrm{C}_{2} \mathrm{mim}\right]\left[\mathrm{NTf}_{2}\right]\right)$ was synthesized according to standard literature procedures ${ }^{12,13}$ and kindly donated by the group of Professor Christopher Hardacre at Queens University, Belfast. [ $\left.\mathrm{C}_{2} \mathrm{mim}\right]\left[\mathrm{NTf}_{2}\right]$ has a melting point of $-3{ }^{\circ} \mathrm{C}$, a viscosity of $34 \mathrm{cP}\left(\right.$ at $20^{\circ} \mathrm{C}$ ) and a conductivity of $8.8 \mathrm{mS} / \mathrm{cm}$ (at 20 $\left.{ }^{\circ} \mathrm{C}\right) .{ }^{12}$ Ultra-pure water with a resistivity of $18.2 \mathrm{M} \Omega \mathrm{cm}$, prepared by an ultra-pure laboratory water purification system (Millipore Pty Ltd., North Ryde, NSW, Australia). Acetonitrile (MeCN, 99.8\%), ferrocene $\left(\mathrm{Fe}\left(\mathrm{C}_{5} \mathrm{H}_{5}\right)_{2}, 98 \%\right.$ purity) and tetra- $N$ butylammonium perchlorate (TBAP, $98 \%$ purity) were purchased from Sigma Aldrich, Australia, and were used as received. Chlorine gas (at concentrations of either $4.5 \%$ or 0.2 $\%$, in nitrogen) was purchased from CAC Gas \& Instrumentation (Auburn, NSW, Australia). High purity nitrogen gas (99.99\%) was purchased from BOC (North Ryde, NSW, Australia).

\subsection{Electrochemical Experiments}

Electrochemical experiments were conducted using a PGSTAT101 Autolab (EcoChemie, The Netherlands) interfaced to a personal computer running NOVA 1.9 software. Experiments were conducted at a temperature of $298( \pm 1) \mathrm{K}$ inside an aluminium Faraday cage placed inside a fume cupboard.

For experiments involving the microelectrode, a two electrode arrangement was employed with a home-made platinum microelectrode $(8.3 \mu \mathrm{m}$ radius $\mathrm{Pt}$ wire encased in glass $)$ as the working electrode and a $0.5 \mathrm{~mm}$ diameter silver wire as a combined reference and counter electrode. The microelectrode was polished on soft lapping pads (Buehler, Illinois) with alumina powder of decreasing size (3,1 and $0.5 \mu \mathrm{m}$, Kemet, NSW, Australia) before 
electrochemical experiments commenced. The electrodes were housed in a glass "T-cell" designed for studying micro quantities (e.g. 20-50 $\mu \mathrm{L}$ ) of ionic liquids in a controlled environment, previously used to study ammonia, ${ }^{14}$ oxygen $^{15}$ and methylamine. ${ }^{16} 30 \mu \mathrm{L}$ of RTIL was used in this study for chlorine gas. The T-cell with the electrode inside was clamped vertically with both the gas inlet and gas outlet connected to PTFE tubing via Swagelok fittings with the outlet line leading to the top of the fume cupboard. Before the introduction of chlorine gas, the cell was purged under high vacuum (high vacuum pump, model ES 50, Edwards) to remove any impurities present in the RTIL and obtain a clean, blank signal. The microelectrode diameter was calibrated electrochemically by using the steady state voltammetry of a $2 \mathrm{mM}$ ferrocene (diffusion coefficient $2.3 \times 10^{-5} \mathrm{~cm}^{2} \mathrm{~s}^{-1}$ at 298 $\mathrm{K})^{17}$ solution in acetonitrile with $0.1 \mathrm{M}$ TBAP. Chronoamperometric transients were recorded using a sample time of $0.01 \mathrm{~s}$. After equilibration at $1.6 \mathrm{~V}$, the potential was stepped to a potential more negative than the reduction peak and the current was measured for $10 \mathrm{~s}$. After deletion of the first 10 data points, the transients were fitted to the Shoup and Szabo equation, ${ }^{18}$ using Origin 6.0 (Microcal Software Inc.), to obtain the diffusion coefficient $(D)$ and the number of electrons multiplied by concentration $(n c)$.

Pt SPEs (product number DRP-550) were purchased from DropSens, Oviedo, Spain. These consist of a silver quasi-reference electrode (RE), a Pt counter (CE) and a 4mm diameter Pt working electrode (WE). The SPEs were housed in a glass "T-cell” previously described. 1920 $10 \mu \mathrm{L}$ of RTIL was dropcast to cover the electrodes, with the RTIL spread over all three electrodes (approximate diameter $8 \mathrm{~mm}$ ). The height of the RTIL is smaller at the edges and larger in the centre of the droplet. However, the average height of the layer (based on the volume and the spread of RTIL) is ca. $0.2 \mathrm{~mm}$, much less than the ca. $1.5-2 \mathrm{~mm}$ above the microelectrode surface. As a result, the time taken for saturation of $\mathrm{Cl}_{2}$ gas was much less on the SPE compared to the microelectrode (see next section). Prior to the introduction of 
chlorine gas, the cell was purged under nitrogen for 90 minutes to remove any impurities present in the RTIL. The SPEs were used without any activation or precleaning.

\subsection{Gas mixing setup}

A similar gas mixing setup as described previously ${ }^{20}$ was used to obtain different concentrations of chlorine. Briefly, two gas cylinders (chlorine and nitrogen) were connected to two separate flowmeters with the aid of PTFE tubes and Swagelok fittings. These two flow meters were then connected to a 'T joint' Swagelok fitting with PTFE tubing to allow mixing of the gases before entering the T-cell. The $\%$ concentration of chlorine that was introduced into the glass cell was calculated using the relative flow rates of the two flow meters. A digital flowmeter (0-1.2 L/min, John Morris Scientific, NSW, Australia) was used for the nitrogen gas and an analogue flowmeter $\left(0-60 \mathrm{~cm}^{3} / \mathrm{min}\right.$, Dwyer, NSW, Australia) made with PTFE was used for chlorine gas. It took approximately 90 minutes for saturation/equilibration to occur for each specific concentration in the case of the microelectrode and 45 mins for the SPEs. Saturation for each concentration was confirmed when two identical CVs for the same concentration were taken 15-20 minutes apart.

\subsection{Safety Considerations}

Chlorine is an extremely corrosive gas and reacts with moisture to form $\mathrm{HCl}$ which corrodes steel. All Swagelok fittings that were connected to the chlorine gas flowmeter were made of PTFE. Gas PTFE tape (Swagelok, Kardinya, WA, Australia) was wrapped around the threads of the metal Swagelok fittings from the chlorine gas cylinder to the regulator to ensure a tight seal and prevent leaks. A Deep Purge System (Chem-Master, Gas Arc Group Ltd, UK) was also added to prevent any corrosion from occurring inside the regulator and the outlet of the chlorine gas cylinder. It was connected directly to the gas cylinder and just before the regulator. The deep purge system is used to purge the system with nitrogen before and after 
experiments so as to remove any residual chlorine, gases or moisture that may be present on the steel surfaces of the regulator and Swagelok fittings.

\section{Results and Discussion}

The RTIL chosen for this study was $\left[\mathrm{C}_{2} \mathrm{mim}\right]\left[\mathrm{NTf}_{2}\right]$ because it has a wide electrochemical window $(>4.5 \mathrm{~V})$, allowing for a large potential range to be examined. It is also one of the least viscous RTILs available, making the gas partitioning time shorter than for other RTILs. In these experiments, chlorine gas is passed over the surface of the RTIL for sufficient time (ca. 90 min on the microelectrode set-up with $30 \mu \mathrm{L}$ RTIL and ca. 45 min on the SPE set-up with $10 \mu \mathrm{L}$ RTIL) to enable the gas to partition into and to reach an equilibrium concentration in the RTIL phase (figure 1). It was shown previously ${ }^{11}$ that chlorine can be reduced in $\left[\mathrm{C}_{2} \mathrm{mim}\right]\left[\mathrm{NTf}_{2}\right]$ on a $\mathrm{Pt}$ microelectrode, producing a reduction wave and a corresponding oxidation peak. This RTIL was employed as the solvent in all experiments described throughout this work. Additionally, Pt was chosen as the electrode material due to the reliable and reproducible voltammetry obtained for chlorine reduction. Experiments on $\mathrm{Au}$ microelectrodes, and $\mathrm{C}$ and $\mathrm{Au}$ SPEs (results not shown) were not ideal since voltammograms on gold were complicated by follow-up chemistry (i.e. formation of gold chloride complexes), and voltammograms on carbon SPEs exhibited a large background capacitive current, as reported previously. ${ }^{19}$

\subsection{Electrochemical reduction of chlorine gas on a Pt microelectrode}

Figure $2 \mathrm{a}$ shows a typical $\mathrm{CV}$ of $\left[\mathrm{C}_{2} \mathrm{mim}\right]\left[\mathrm{NTf}_{2}\right]$ equilibrated with $4.5 \%$ chlorine gas (nitrogen fill) at a scan rate of $0.1 \mathrm{~V} / \mathrm{s}$ when scanned from $1.5 \mathrm{~V}$ to $-0.4 \mathrm{~V}$ and back to $1.5 \mathrm{~V}$. The response in the absence of chlorine is shown as the dotted line. It can be seen that there is a steady state reduction wave and a peak shaped oxidation. These reactions correspond to the two electron reduction of chlorine to chloride and the oxidation of chloride to chlorine. The 
absence of the oxidation peak when the potential is initially scanned in the positive direction indicates that it is a direct consequence of the reduction process. No other processes were observed in either the oxidative or reductive windows before the breakdown of the solvent.

Due to the high reactivity of chlorine gas with water, it is possible that chlorine may react with water impurities naturally present in the RTIL. Hossain et al. ${ }^{21}$ studied the oxidation of chloride in wet RTILs (containing ambient water) and showed that the electrogenerated chlorine reacted to form various oxychloride compounds. They found that the follow-up chemical reactions were less prevalent when the RTIL was dried under high-vacuum conditions. It has been reported that even after being evacuated (as in the case of the experiments reported in Figure 2), ca. $105 \mathrm{ppm}$ of water remains in $\left[\mathrm{C}_{2} \mathrm{mim}\right]\left[\mathrm{NTf}_{2}\right]{ }^{22}$ This is larger than the concentrations of chlorine in the RTIL used in this work (see next section). However, the CVs in Figure 2 show no evidence of reaction of chlorine with water, since they are stable over time, and the relative currents for the reduction and oxidation processes remain the same at different concentrations of chlorine (see next section). Also, no additional reduction peaks (indicative of oxychloride species) ${ }^{21}$ are observed after the chlorine reduction peak. It is likely that the $105 \mathrm{ppm}$ of water in $\left[\mathrm{C}_{2} \mathrm{mim}\right]\left[\mathrm{NTf}_{2}\right]$ stays bound to the ions of the RTIL and does not react with chlorine. The behavior of water in RTILs has been the subject of several recent articles, ${ }^{23,24}$ which suggest that water behaves differently to bulk water at trace concentrations in RTILs, and that the water molecules are likely bound to the RTIL through hydrogen bonding interactions.

It is important to note here that due to the high viscosity of RTILs, when used with a microelectrode, steady-state current seen on a CV cannot be taken as the true steady state limiting current. True steady state behaviour is often only seen at very slow scan rates and follows the inequality ${ }^{7}$ 


$$
v \ll \frac{R T D}{n F r_{d}^{2}}
$$

where $v$ is the scan rate, $R$ is the universal gas constant, $T$ is the absolute temperature, $F$ is the Faraday constant, $D$ is the diffusion coefficient and $r_{d}$ is the radius of the electrode. This behaviour in RTILs was very well shown in the work by Evans et al. ${ }^{25}$ For chlorine gas in the current study, using the values of $T$ as $293 \mathrm{~K}, D$ as $2.6 \times 10^{-10} \mathrm{~m}^{2} \mathrm{~s}^{-1}$ (as determined in a later section) and $r_{d}$ as $8.3 \times 10^{-6} \mathrm{~m}$, a value of $0.048 \mathrm{~V} / \mathrm{s}$ for the scan rate is required for true steady state behaviour. This is demonstrated by the CVs in Fig $2 \mathrm{~b}$, where at a scan rate of $0.05 \mathrm{~V} / \mathrm{s}$ steady state behaviour is seen and at progressively higher scan rates, the steady state current changes to peak-shaped. However for the reverse peak (chloride oxidation) the process is peak-shaped at all scan rates studied, due to the slower diffusion coefficient of chloride $\left(\sim 10^{-}\right.$ $\left.{ }^{11} \mathrm{~m}^{2} \mathrm{~s}^{-1}\right)^{26}$ compared to chlorine $\left(\sim 10^{-10} \mathrm{~m}^{2} \mathrm{~s}^{-1}\right)$.

The relatively high currents obtained for the reduction indicates that chlorine has a high solubility in $\left[\mathrm{C}_{2} \mathrm{mim}\right]\left[\mathrm{NTf}_{2}\right]$, which was also reported previously by Huang et al. ${ }^{11}$ Figure $2 \mathrm{~b}$ shows the electrochemical reduction of $4.5 \%$ chlorine gas at various scan rates from $0.05 \mathrm{~V} / \mathrm{s}$ to $3 \mathrm{~V} / \mathrm{s}$. The voltammetry goes from steady state at low scan rates to transient at high scan rates, as is often observed for gases in RTILs on microelectrodes and described by the inequality in equation 4 . The maximum current obtained for the reductive process at various scan rates was plotted against the square root of scan rate and a linear response was obtained, suggesting that it is a one-dimensional diffusion controlled process at these scan rates (inset, Figure $2 \mathrm{~b}$ ). This is in contrast to that observed by Huang et al. ${ }^{11}$ for $100 \% \mathrm{Cl}_{2}$ in the gas phase. It is thought that the difference in behaviour is due to the different concentrations employed. In the present experiments, $4.5 \%$ chlorine gas is used which is $>20 \times$ less than that used by Huang et $\mathrm{al}^{11}$ (100\%), assuming partitioning between the gas and RTIL phases is linear. This means that there is less (or no) opportunity for adsorption of $\mathrm{Cl}_{2}$ (equation 2) onto 
the electrode surface at the lower concentrations employed here. It is likely that the $\mathrm{Cl}_{2}$ molecules are freely diffusing in solution as indicated by the diffusion dependent reduction current. This is very important as it signifies that chlorine behaves differently at lower concentrations and indicates that this electrochemical process may be of analytical interest. It is also worthwhile to note that the CVs (Figure 2) did not display any pre-wave or post-wave peaks, which are useful indicators of adsorption processes accompanying electron transfer reactions. The reverse peak, which is due to the oxidation of chloride, also increases with increasing scan rates and is found to be a one-dimensional diffusion controlled process as a plot of current vs square root of scan rate produced a linear response $\left(\mathrm{R}^{2}>0.99\right)$.

\subsection{Analytical performance of chlorine reduction on a Pt microelectrode}

The analytical performance of the chlorine reduction in $\left[\mathrm{C}_{2} \mathrm{mim}\right]\left[\mathrm{NTf}_{2}\right]$ was studied by $\mathrm{CV}$ across a range of concentrations (Figure 3). It can be seen that as the concentration of $\mathrm{Cl}_{2}$ increased, the current for both the reduction and oxidation processes increased. Figure 4 shows the chronoamperometric transients obtained for ten different concentrations of chlorine gas (173 to $3333 \mathrm{ppm})$ after the potential was stepped from $1.6 \mathrm{~V}$ to $0.1 \mathrm{~V}$ following a $20 \mathrm{~s}$ equilibration time at 1.6 V. Plots of current versus concentration for both the CV (steady-state reduction current) and chronoamperometry (reduction current at $10 \mathrm{~s}$ ) experiments are shown in Figure 5, which display excellent linear response behaviour $\left(\mathrm{R}^{2}>0.99\right)$. The limits of detection (LODs) were then obtained for the $\mathrm{CV}$ and chronoamperometry methods based on three times the standard deviation of the line of best fit. Values for the LOD of $106 \mathrm{ppm}$ from CV and 112 ppm from chronoamperometry were obtained. Additionally, from the slopes of the graphs, the sensitivity was determined to be $6.8( \pm 0.08) \times 10^{-13} \mathrm{~A} / \mathrm{ppm}$ from $\mathrm{CV}$ and $7.2( \pm 0.09) \times 10^{-13} \mathrm{~A} / \mathrm{ppm}$ from chronoamperometry. The LODs obtained, together with the high solubility, suggest that this RTIL may be a suitable solvent for the electrochemical 
detection of chlorine. Other more sensitive methods, such as square wave voltammetry and differential pulse voltammetry, could be used in future work to improve the LODs.

\subsection{Chronoamperometric analysis of the reduction of chlorine on a Pt microelectrode}

The experimentally obtained chronoamperometric transients were fitted with the Shoup and Szabo ${ }^{18}$ expression and ten different diffusion coefficient $(D)$ values between $1.4 \times 10^{-10} \mathrm{~m}^{2} \mathrm{~s}^{-1}$ and $3.2 \times 10^{-10} \mathrm{~m}^{2} \mathrm{~s}^{-1}$ were obtained for the various concentrations. Slight variations in the 'best fit' diffusion coefficients using the Shoup and Szabo ${ }^{18}$ expression are possible, as reported by Xiong et al. ${ }^{27}$ In order to ascertain which $D$ value is the most accurate for $\mathrm{Cl}_{2}$ gas, each of the ten $D$ values were fixed, and the ten experimental chronoamperometric transients were refitted to the Shoup and Szabo ${ }^{18}$ expression (100 fits in total). The best fit (measured using the highest total $\mathrm{R}^{2}$ values) was found for a diffusion coefficient of $2.6 \times 10^{-10} \mathrm{~m}^{2} \mathrm{~s}^{-1}$ (also the midpoint of the $D$ s obtained from the original fittings). Figure 4 shows the fits for all ten concentrations using this $D$ value (solid line = experimental; circles $=$ theoretical fit to the Shoup and Szabo expression). Diffusion coefficients of the order $10^{-10} \mathrm{~m}^{2} \mathrm{~s}^{-1}$ are commonly observed for gases in RTILs, ${ }^{28}$ suggesting that this is a reasonable estimate for chlorine gas in RTILs. The fitting also gave $n c$ values for all ten concentrations. Assuming a 2-electron process, concentration values between 0.09 and $1.38 \mathrm{mM}$ in $\left[\mathrm{C}_{2} \mathrm{mim}\right]\left[\mathrm{NTf}_{2}\right]$ were obtained (see Table 1). If the concentration scales linearly with the gas-phase concentration, a solubility of approximately $405 \mathrm{mM}$ for chlorine in $\left[\mathrm{C}_{2} \mathrm{mim}\right]\left[\mathrm{NTf}_{2}\right]$ is estimated, which can be compared to other gas solubilities in RTILs, e.g. hydrogen $(4.2 \mathrm{mM}){ }^{29}$ sulfur dioxide $(230 \mathrm{mM})^{30}$ and hydrogen sulphide $(529 \mathrm{mM}),{ }^{31}$ as well as the estimate of $1-10 \mathrm{M}$ for $\mathrm{Cl}_{2}$ that was predicted by Huang et al. ${ }^{11}$ 


\subsection{Henry's Law constant for Chlorine in $\left[\mathrm{C}_{2} \mathrm{mim}\right]\left[\mathrm{NTf}_{2}\right]$}

Using the concentration values obtained via the chronoamperometric analysis, the partition coefficient of $\mathrm{Cl}_{2}$ gas between the gas phase and $\left[\mathrm{C}_{2} \mathrm{mim}\right]\left[\mathrm{NTf}_{2}\right]$ can be obtained. This is also known as the Henry's law dimensionless "volatility constant" ( $H^{\mathrm{cc}}$ equation 5$),{ }^{32-34}$ which is a measure of the ability of the gas to escape from the liquid phase.

$$
H^{\mathrm{cc}}=\frac{\text { concentration of gas in the gas phase }}{\text { concentration of gas in the liquid phase }}
$$

Figure 6 shows the relationship between the concentration of chlorine in the gas phase and the ionic liquid phase. The concentration of chlorine in the gas phase was determined by the relative flow rates of gas from the chlorine and nitrogen gas cylinders. The concentration of the gas in the RTIL phase was determined by fitting the chronoamperometric transients to the Shoup and Szabo ${ }^{18}$ expression (see Table 1) and then converting to units of ppm.

It was highly encouraging that excellent linearity was obtained. Since the plot in Figure 6 was obtained using two different cylinders (lower 5 concentrations from a $2000 \mathrm{ppm} \mathrm{Cl}_{2}$ cylinder and higher 5 concentrations from a $4.5 \% \mathrm{Cl}_{2}$ cylinder), this confirms the validity of our gas mixing system for dilution with nitrogen gas. The slope of the line from this relationship also provides $H^{\text {cc } 33}$. A value of 35 was obtained, which means that the concentration of chlorine is 35 times higher in the gas phase than in the RTIL phase. Although the solubility values for various gases in RTILs have been reported in the review by Lei et al. ${ }^{35}$, an experimental Henry's constant value for chlorine gas in RTILs was not reported. Hence, it is believed that this is the first time such a value is reported. This electrochemical method provides a relatively simple way to measure Henry's constants for highly toxic gases. 


\subsection{Electrochemical reduction of chlorine on a Pt SPE}

Following on from the elucidation of the electrochemical behaviour on a Pt microelectrode, the performance on Pt SPEs was investigated for their suitability for chlorine gas sensing.

Figure $7 \mathrm{a}$ shows the electrochemical reduction of $4.5 \%$ chlorine gas on a Pt SPE at 100 $\mathrm{mV} / \mathrm{s}$. It can be seen that there is a reduction peak at $0.34 \mathrm{~V}$ and an oxidation peak at $0.72 \mathrm{~V}$ with a peak to peak separation of $0.38 \mathrm{~V}$. The reduction process on the SPE is peak-shaped due to the contribution of linear diffusion on the large area SPE working electrode (diameter $4 \mathrm{~mm}$ ). Figure $7 \mathrm{~b}$ shows the electrochemical reduction of $4.5 \%$ chlorine gas at various scan rates from $0.05 \mathrm{~V} / \mathrm{s}$ to $3 \mathrm{~V} / \mathrm{s}$. The current obtained for the reductive process at the various scan rates was plotted against the square root of scan rate, and similar to the microelectrode, a linear response was obtained (see inset Figure $7 \mathrm{~b}$ ) which suggests that the process is also onedimensional diffusion controlled. The similar electrochemical behaviour seen on both the SPE and the microelectrode suggests that the mechanism for the reduction of chlorine gas is the same at this concentration, which is encouraging for sensing purposes. Additionally, the charges under the curves for both the reductive $(0.999 \mathrm{mC})$ and oxidative processes $(0.950 \mathrm{C})$ are similar, suggesting that the process is chemically reversible. It is important to note that in previous work, the reduction of oxygen on SPEs was different to that on microelectrodes in this RTIL (due to a reaction of the reduction product with the materials in the SPE paste) and indicated that the detection of oxygen on Pt SPEs may not be feasible for long-term studies ${ }^{20}$.

The currents obtained for chlorine are approximately 5 orders of magnitude larger on the SPE compared to the microelectrode, meaning that any possible build-up of chloride (reduction product) would be more significant on the SPE. However, the reaction was found to be chemically reversible on both micro and SPE surfaces, meaning that any electrogenerated chloride could be oxidised simply by applying an appropriate potential (i.e. more positive 
than the oxidation peak). As a result, it is recommended that either (a) a full CV cycle is completed if using cyclic voltammetry as the detection method, or (b) biasing at a positive potential is performed if chronoamperometry is used. This would prevent a build up of chloride within the RTIL, which is especially important, as halide impurities present in RTILs are known to alter physical properties such as viscosity and electrochemical window. ${ }^{36}$

\subsection{Analytical performance of chlorine on a Pt SPE}

Figure 8a shows typical CVs of five different concentrations of chlorine gas (173 to 1583 ppm) on a Pt SPE. It can be seen that the current of both the reduction and the oxidation processes increases with the concentration of the gas. There is also the presence of a prepeak/shoulder on the reductive scan (at ca. $0.75 \mathrm{~V}$, not present in the absence of chlorine) that is more visible at lower concentrations of chlorine, but is not observed at higher concentrations (see Figure 7). The current of this peak does not seem to change significantly in the concentration range studied (173 and $1583 \mathrm{ppm})$. This is attributed to the response of chlorine on the non-ideal screen-printed surface (since it contains other materials, e.g. polymers, binders, in addition to the Pt metal particles). The presence of this peak might affect the sensing of chlorine at low ppm concentrations (e.g. less than $173 \mathrm{ppm}$ ).

Figure $8 \mathrm{~b}$ shows the calibration graph obtained on a Pt SPE using the reduction peak currents for the same concentration range studied previously on a Pt microelectrode. It can be seen that a linear behaviour is observed, with $\mathrm{R}^{2}>0.99$, a sensitivity of $1.01( \pm 0.02) \times 10^{-8} \mathrm{~A} / \mathrm{ppm}$ and a LOD of $137 \mathrm{ppm}$. While the LOD is comparable to that obtained at a microelectrode (106 ppm), the sensitivity is higher on the SPE, which is a consequence of the geometric sizes of the two electrodes. Normalizing the CV sensitivities for the geometric areas of the respective electrodes yields values of $3.15 \times 10^{-7} \mathrm{~A} / \mathrm{cm}^{2} \cdot \mathrm{ppm}$ and $8.08 \times 10^{-8} \mathrm{~A} / \mathrm{cm}^{2} \cdot \mathrm{ppm}$ for the microelectrode and SPE respectively, which indicates that the microelectrode has a higher 
sensitivity due to the higher current density on the smaller electrode. The excellent linearity and limits of detection similar to "ideal" microelectrodes suggest that Pt SPEs may be useful low-cost platforms for the detection of chlorine, but detection at low ppm concentrations may be limited due to the appearance of a pre-peak in the voltammetry.

\section{Conclusions}

The electrochemical behaviour of chlorine gas has been studied on Pt electrodes. On a Pt microdisk electrode, a high current for the reduction of chlorine suggests a very high solubility in the RTIL. CVs at lower concentrations $(<4.5 \%$ in the gas phase) showed no unusual scan rate dependence, as was observed previously at higher concentrations of chlorine $^{11}$. This is encouraging for sensing applications, and prompted the investigation of linear calibration behaviour and determination of LODs. LODs of 106 and 112 ppm were obtained from $\mathrm{CV}$ and chronoamperometric methods, respectively, while the responses were linear over the ranges of ca. $174 \mathrm{ppm}$ to $3333 \mathrm{ppm}$. Chronoamperometric transients were fitted with the Shoup and Szabo ${ }^{18}$ expression to yield a diffusion coefficient of $2.6 \times 10^{-10} \mathrm{~m}^{2} \mathrm{~s}^{-}$ ${ }^{1}$ and equilibrated concentrations in the liquid phase. Comparison of these liquid-phase concentrations with their corresponding gas-phase concentrations enabled the determination of the Henry's law dimensionless "volatility constant" for chlorine, which has not been reported before. By choosing a RTIL with a lower $H^{\mathrm{cc}}$ value, better preconcentration of chlorine from the gas phase, and a lower limit of detection may be achieved. The electrochemical behaviour was also investigated on a Pt SPE, with clear reduction and oxidation peaks present. Similar behaviour to that seen on the microelectrode suggests that the mechanism is the same on the SPE. The analytical utility of chlorine reduction was also determined on the Pt SPE and a LOD of $137 \mathrm{ppm}$ was obtained. These results suggest that low-cost SPEs might be utilised for chlorine sensing. 


\section{Author Information}

Corresponding Author - E-mail: d.silvester-dean@curtin.edu.au

\section{Author Contributions}

K.M. carried out all experiments and made the figures. K.M, D.W.M.A and D.S.S all contributed to design of experiments, the conceptual understanding and writing of the paper.

\section{Acknowledgments}

K.M. thanks Curtin University for the award of a Curtin International Postgraduate Research

Scholarship and D.S.S. thanks the Australian Research Council for funding via a Discovery Early Career Research Award (DE120101456). 
Table of Contents Image
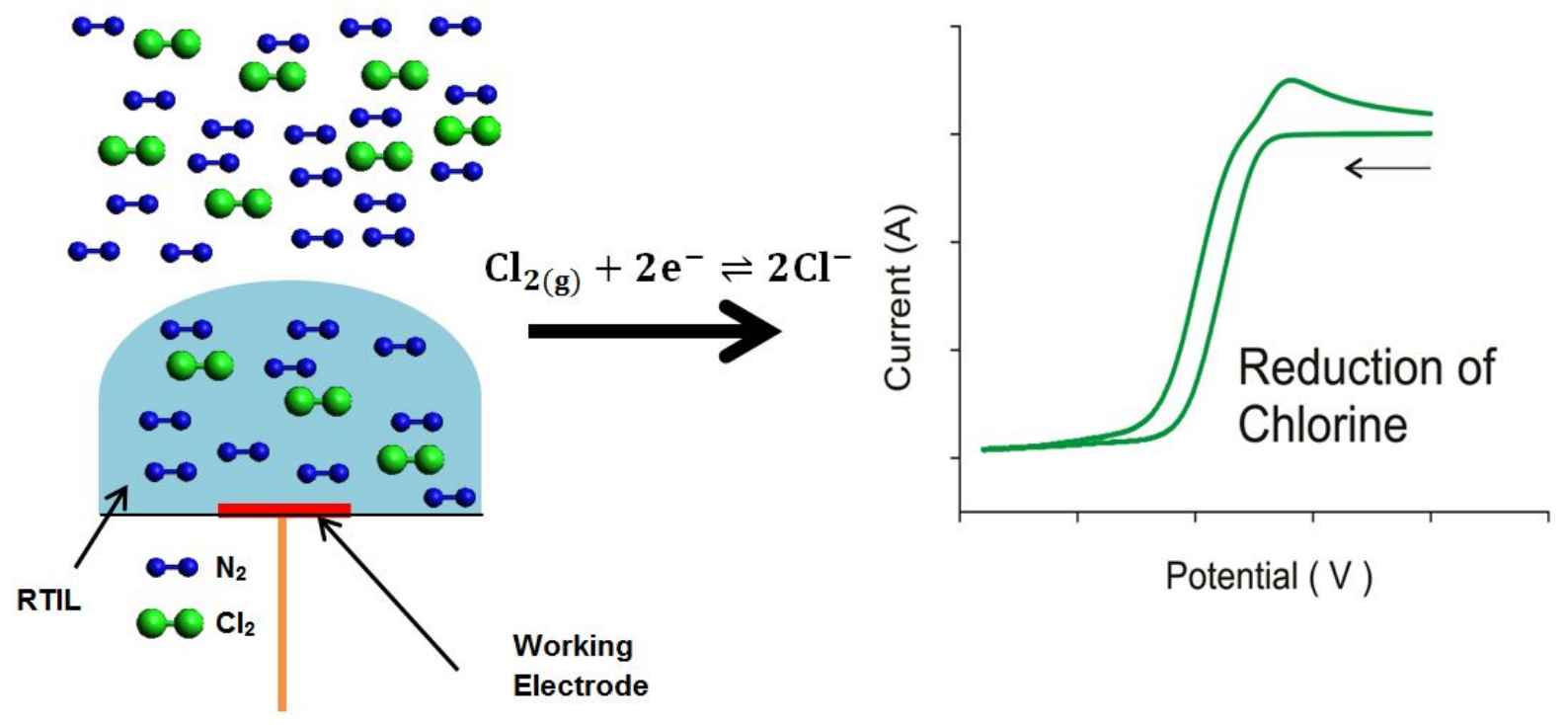


\section{References}

(1) Das, R.; Blanc, P. D.: Chlorine gas exposure and the lung: A review. Toxicol. Ind. Health 1993, 9, 439-455.

(2) White, C. W.; Martin, J. G.: Chlorine gas inhalation. Proc. Am. Thorac. Soc. 2010, 7, 257-263.

(3) Hedges, J. R.; Morrissey, W. L.: Acute chlorine gas exposure. J. Am. Coll. Emer. 1979, 8, 59-63.

(4) Zoffoli, J. P.; Latorre, B. A.; Rodrguez, E. J.; Aldunce, P.: Modified atmosphere packaging using chlorine gas generators to prevent Botrytis cinerea on table grapes. Postharvest Biol.Tec. 1999, 15, 135-142.

(5) Lee, S.-Y.; Costello, M.; Kang, D.-H.: Efficacy of chlorine dioxide gas as a sanitizer of lettuce leaves. J. Food Protect. 2004, 67, 1371-1376.

(6) Sparrow, A.: Syria: Death from Assad's chlorine. NEW YORK REVIEW OF BOOKS 2015, $62,40-42$.

(7) Buzzeo, M. C.; Evans, R. G.; Compton, R. G.: Non-haloaluminate room-temperature ionic liquids in electrochemistry-A review. ChemPhysChem 2004, 5, 1106-1120.

(8) Plechkova, N. V.; Seddon, K. R.: Applications of ionic liquids in the chemical industry. Chem. Soc. Rev. 2008, 37, 123-150.

(9) Silvester, D. S.; Compton, R. G.: Electrochemistry in room temperature ionic liquids: A review and some possible applications. Z. Phys. Chem. 2006, 220, 1247-1274.

(10) Sereno, L.; Macagno, V. A.; Giordano, M. C.: Electrochemical behaviour of the chloride/chlorine system at platinum electrodes in acetonitrile solutions. Electrochim. Acta 1972, 17, 561-575.

(11) Huang, X.-J.; Silvester, D. S.; Streeter, I.; Aldous, L.; Hardacre, C.; Compton, R. G.: Electroreduction of chlorine gas at platinum electrodes in several room temperature ionic liquids: Evidence of strong adsorption on the electrode surface revealed by unusual voltammetry in which currents decrease with increasing voltage scan rates. J. Phys. Chem. C 2008, 112, 19477-19483.

(12) Bonhôte, P.; Dias, A.-P.; Papageorgiou, N.; Kalyanasundaram, K.; Grätzel, M.: Hydrophobic, highly conductive ambient-temperature molten salts. Inorg. Chem. 1996, 35, 11681178.

(13) MacFarlane, D. R.; Meakin, P.; Sun, J.; Amini, N.; Forsyth, M.: Pyrrolidinium imides: A new family of molten salts and conductive plastic crystal phases. J. Phys. Chem. B 1999, 103, 41644170.

(14) Ji, X.; Silvester, D. S.; Aldous, L.; Hardacre, C.; Compton, R. G.: Mechanistic studies of the electro-oxidation pathway of ammonia in several room-temperature ionic liquids. J. Phys. Chem. C 2007, 111, 9562-9572.

(15) Huang, X.-J.; Rogers, E. I.; Hardacre, C.; Compton, R. G.: The reduction of oxygen in various room temperature ionic liquids in the temperature range 293-318 K: Exploring the applicability of the Stokes-Einstein relationship in room temperature ionic liquids. J. Phys. Chem. $B$ 2009, 113, 8953-8959.

(16) Murugappan, K.; Kang, C.; Silvester, D. S.: Electrochemical oxidation and sensing of methylamine gas in room temperature ionic liquids. J. Phys. Chem. C 2014, 118, 19232-19237.

(17) Sharp, M.: Determination of the charge-transfer kinetics of ferrocene at platinum and vitreous carbon electrodes by potential steps chronocoulometry. Electrochim. Acta 1983, 28, 301-308.

(18) Shoup, D.; Szabo, A.: Chronoamperometric current at finite disk electrodes. J. Electroanal. Chem. 1982, 140, 237-245.

(19) Murugappan, K.; Lee, J.; Silvester, D. S.: Comparative study of screen printed electrodes for ammonia gas sensing in ionic liquids. Electrochem. Commun. 2011, 13, 1435-1438. 
(20) Lee, J.; Murugappan, K.; Arrigan, D. W. M.; Silvester, D. S.: Oxygen reduction voltammetry on platinum macrodisk and screen-printed electrodes in ionic liquids: Reaction of the electrogenerated superoxide species with compounds used in the paste of Pt screen-printed electrodes? Electrochim. Acta 2013, 101, 158-168.

(21) Hossain, M. M.; Hosseini Bab Anari, E.; Aldous, L.: Electrochemistry of chloride in ambient room temperature ionic liquids: Formation of oxychloride species. Electrochem. Commun. 2013, 34, 331-334.

(22) O'Mahony, A. M.; Silvester, D. S.; Aldous, L.; Hardacre, C.; Compton, R. G.: Effect of water on the electrochemical window and potential limits of room-temperature ionic liquids. J. Chem. Eng. Data 2008, 53, 2884-2891.

(23) Reid, J. E. S. J.; Walker, A. J.; Shimizu, S.: Residual water in ionic liquids: clustered or dissociated? PhysChemChemPhys 2015, 17, 14710-14718.

(24) Köddermann, T.; Wertz, C.; Heintz, A.; Ludwig, R.: The association of water in ionic liquids: A reliable measure of polarity. Angew. Chem. Int. Ed. 2006, 45, 3697-3702.

(25) Evans, R. G.; Klymenko, O. V.; Saddoughi, S. A.; Hardacre, C.; Compton, R. G.: Electroreduction of oxygen in a series of room temperature ionic liquids composed of group 15centered cations and anions. J. Phys. Chem. B 2004, 108, 7878-7886.

(26) Villagrán, C.; Banks, C. E.; Hardacre, C.; Compton, R. G.: Electroanalytical determination of trace chloride in room-temperature ionic liquids. Anal. Chem. 2004, 76, 1998-2003.

(27) Xiong, L.; Aldous, L.; Henstridge, M. C.; Compton, R. G.: Investigation of the optimal transient times for chronoamperometric analysis of diffusion coefficients and concentrations in nonaqueous solvents and ionic liquids. Anal. Methods 2012, 4, 371-376.

(28) Rogers, E. I.; O'Mahony, A. M.; Aldous, L.; Compton, R. G.: Amperometric gas detection using room temperature ionic liquid solvents. ECS Trans. 2010, 33, 473-502.

(29) Silvester, D. S.; Ward, K. R.; Aldous, L.; Hardacre, C.; Compton, R. G.: The electrochemical oxidation of hydrogen at activated platinum electrodes in room temperature ionic liquids as solvents. J. Electroanal. Chem. 2008, 618, 53-60.

(30) Barrosse-Antle, L. E.; Silvester, D. S.; Aldous, L.; Hardacre, C.; Compton, R. G.: Electroreduction of sulfur dioxide in some room-temperature ionic liquids. J. Phys. Chem. C 2008, $112,3398-3404$.

(31) O'Mahony, A. M.; Silvester, D. S.; Aldous, L.; Hardacre, C.; Compton, R. G.: The electrochemical reduction of hydrogen sulfide on platinum in several room temperature ionic liquids. J. Phys. Chem. C 2008, 112, 7725-7730.

(32) Oliferenko, A. A.; Oliferenko, P. V.; Seddon, K. R.; Torrecilla, J. S.: Prediction of gas solubilities in ionic liquids. PhysChemChemPhys 2011, 13, 17262-17272.

(33) Sander, R.: Compilation of Henry's law constants, version 3.99. Atmos. Chem. Phys. Discuss. 2014, 14, 29615-30521.

(34) Smith, F. L.; Harvey, A. H.: Avoid common pitfalls when using Henry's law. Chem. Eng. Prog. 2007, 103, 33-39.

(35) Lei, Z.; Dai, C.; Chen, B.: Gas solubility in ionic liquids. Chem. Rev. 2013, 114, 12891326.

(36) Barrosse-Antle, L. E.; Bond, A. M.; Compton, R. G.; O 'Mahony, A. M.; Rogers, E. I.; Silvester, D. S.: Voltammetry in room temperature ionic liquids: comparisons and contrasts with conventional electrochemical solvents. Chem. Asian J. 2010, 5, 202-230. 


\section{Tables}

Table 1: Concentration of chlorine gas in the RTIL phase obtained by fitting chronoamperometric transients from figure 4.

\begin{tabular}{c|c|c}
$\begin{array}{c}\text { Conc. Of } \mathbf{C l}_{\mathbf{2}} \text { in gas } \\
\text { phase (ppm) }\end{array}$ & $\begin{array}{c}\text { Conc. Of } \mathbf{C l}_{\mathbf{2}} \text { in } \\
\text { RTIL phase }(\mathbf{m M})\end{array}$ & $\begin{array}{c}\mathbf{R}^{\mathbf{2}} \text { Values for } \\
\text { fitting }\end{array}$ \\
\hline 174 & 0.09 & 0.91 \\
444 & 0.22 & 0.97 \\
726 & 0.34 & 0.99 \\
1065 & 0.47 & 0.99 \\
1583 & 0.63 & 0.99 \\
1915 & 0.80 & 0.99 \\
2143 & 0.89 & 0.99 \\
2432 & 1.01 & 0.99 \\
2813 & 1.17 & 0.99 \\
3333 & 1.38 & 0.99
\end{tabular}




\section{List of Figures}

Figure 1: Cartoon showing the equilibrium attained between the gas molecules in the gaseous phase and RTIL phase.

Figure 2: $\mathrm{CV}$ for the reduction of $4.5 \%(4,500 \mathrm{ppm})$ chlorine gas (nitrogen fill) on a $8.3 \mu \mathrm{m}$ radius $\mathrm{Pt}$ electrode in $\left[\mathrm{C}_{2} \mathrm{mim}\right]\left[\mathrm{NTf}_{2}\right]$ a) at a scan rate of $0.1 \mathrm{~V} / \mathrm{s}$ and b) at varying scan rates between 0.05-3 V/s. Dashed line is the response in the absence of chlorine. The inset in $b$ shows the plot of current vs square root of scan rate.

Figure 3: CVs for the reduction of chlorine gas $(174-1583 \mathrm{ppm})$ on a $8.3 \mu \mathrm{m}$ radius $\mathrm{Pt}$ electrode in $\left[\mathrm{C}_{2} \mathrm{mim}\right]\left[\mathrm{NTf}_{2}\right]$ at a scan rate of $0.1 \mathrm{~V} / \mathrm{s}$. Dashed line is the response in the absence of chlorine.

Figure 4: Chronoamperometric transients for the reduction of ten different concentrations of chlorine gas (174 -3333 ppm) in the RTIL $\left[\mathrm{C}_{2} \mathrm{mim}\right]\left[\mathrm{NTf}_{2}\right]$. The potential was stepped from $1.6 \mathrm{~V}$ to $-0.1 \mathrm{~V}$. Experimental (-) and fitted (using $2.6 \times 10^{-10} \mathrm{~m}^{2} \mathrm{~s}^{-1}$ as $D$ ) theoretical (o) data following the Shoup and Szabo expression. ${ }^{18}$

Figure 5: Calibration plots (current vs concentration) for the reduction of chlorine gas (174 3333 ppm) obtained from the a) CV and b) chronoamperometric method.

Figure 6: A plot of the concentration of chlorine in the gas phase (ppm) vs the RTIL phase (ppm). Concentrations in the RTIL phase were obtained from fitting chronoamperometric transients in Figure 4 to the Shoup and Szabo expression. ${ }^{18}$

Figure 7: $\mathrm{CV}$ for the reduction of $4.5 \%$ chlorine gas (nitrogen fill) on a Pt SPE in $\left[\mathrm{C}_{2} \mathrm{mim}\right]\left[\mathrm{NTf}_{2}\right]$ a) at a scan rate of $0.1 \mathrm{~V} / \mathrm{s}$ and $\mathrm{b}$ ) at varying scan rates between $0.05-3 \mathrm{~V} / \mathrm{s}$. Dotted line is the response in the absence of chlorine. The inset in $b$ shows the plot of square root of scan rate vs current.

Figure 8: a) CVs for the reduction of chlorine gas (174 -1583 ppm) on a Pt SPE in $\left[\mathrm{C}_{2} \mathrm{mim}\right]\left[\mathrm{NTf}_{2}\right]$ at a scan rate of $0.1 \mathrm{~V} / \mathrm{s}$. Dashed line is the response in the absence of chlorine. b) Calibration plot obtained for the reduction of chlorine gas (174 -3333 ppm) using the limiting/peak current from CV on a Pt SPE. 


\section{Figures}

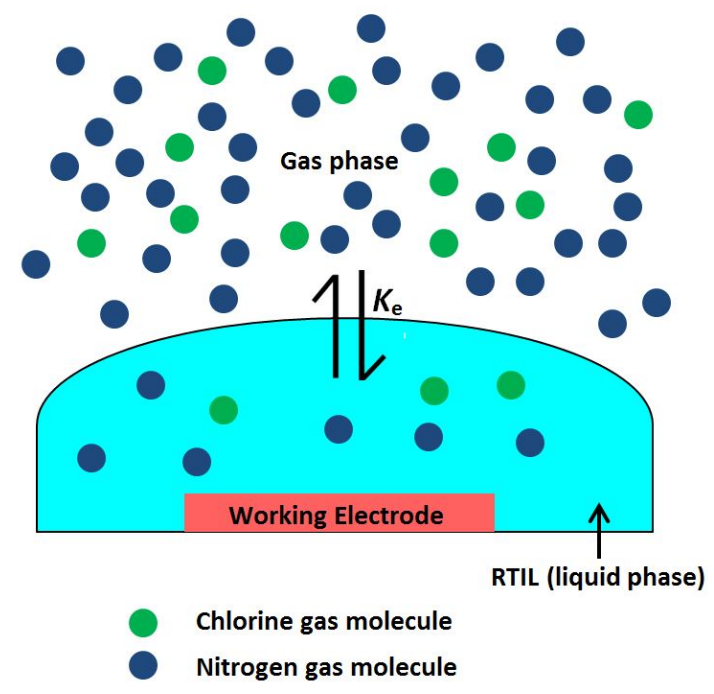

Figure 1: Cartoon showing the equilibrium attained between the gas molecules in the gaseous phase and RTIL phase. 


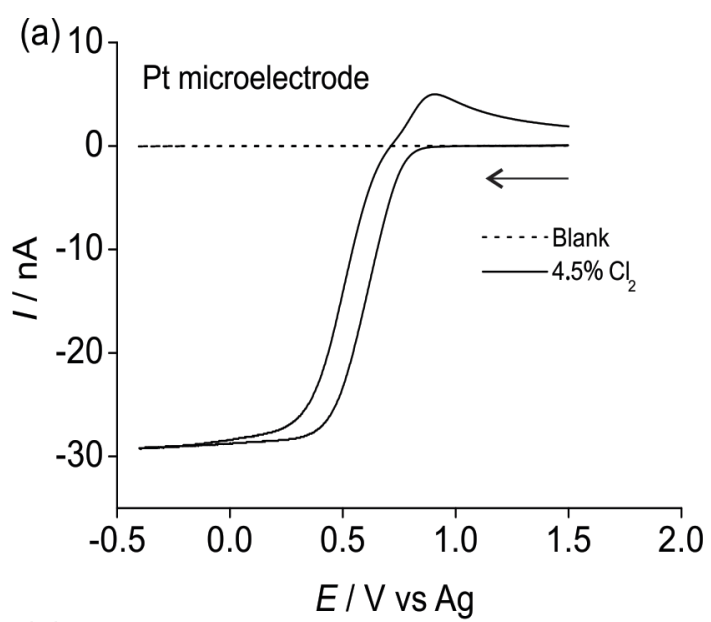

(b)

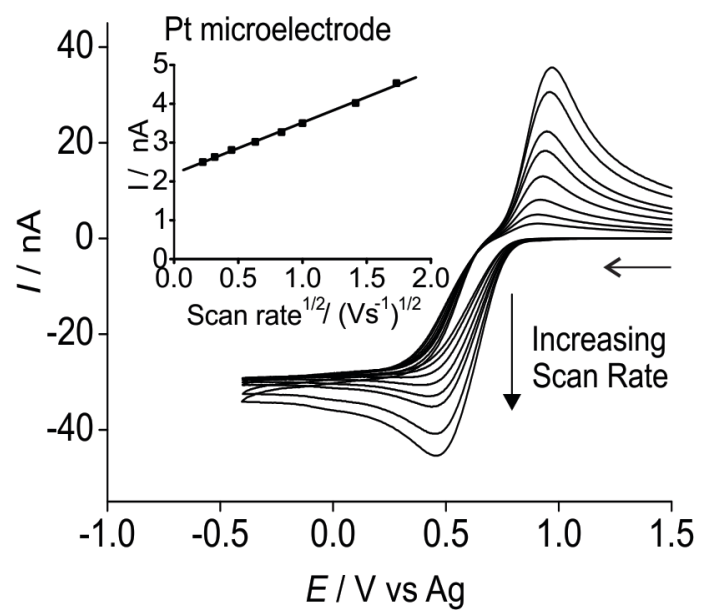

Figure 2: $\mathrm{CV}$ for the reduction of $4.5 \%(4,500 \mathrm{ppm})$ chlorine gas (nitrogen fill) on a $8.3 \mu \mathrm{m}$ radius $\mathrm{Pt}$ electrode in $\left[\mathrm{C}_{2} \mathrm{mim}\right]\left[\mathrm{NTf}_{2}\right]$ a) at a scan rate of $0.1 \mathrm{~V} / \mathrm{s}$ and $\mathrm{b}$ ) at varying scan rates between $0.05-3$ $\mathrm{V} / \mathrm{s}$. Dashed line is the response in the absence of chlorine. The inset in $\mathrm{b}$ shows the plot of current vs square root of scan rate. 


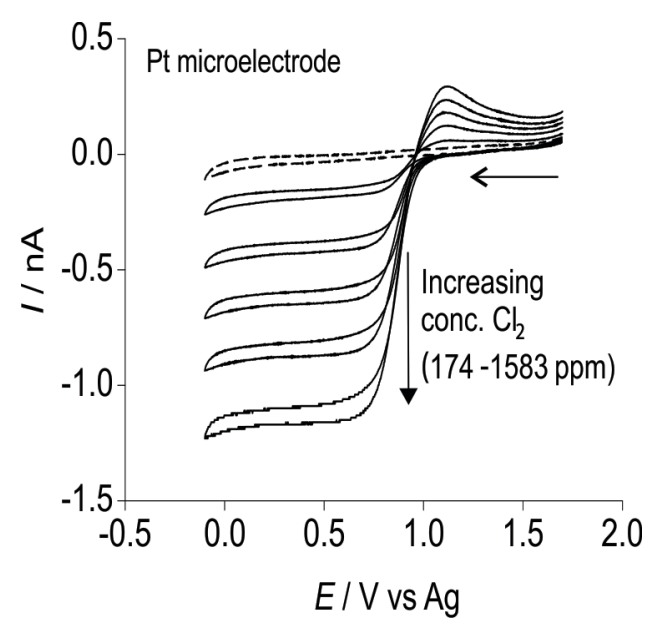

Figure 3: CVs for the reduction of chlorine gas $(174-1583 \mathrm{ppm})$ on a $8.3 \mu \mathrm{m}$ radius Pt electrode in $\left[\mathrm{C}_{2} \mathrm{mim}\right]\left[\mathrm{NTf}_{2}\right]$ at a scan rate of $0.1 \mathrm{~V} / \mathrm{s}$. Dashed line is the response in the absence of chlorine.

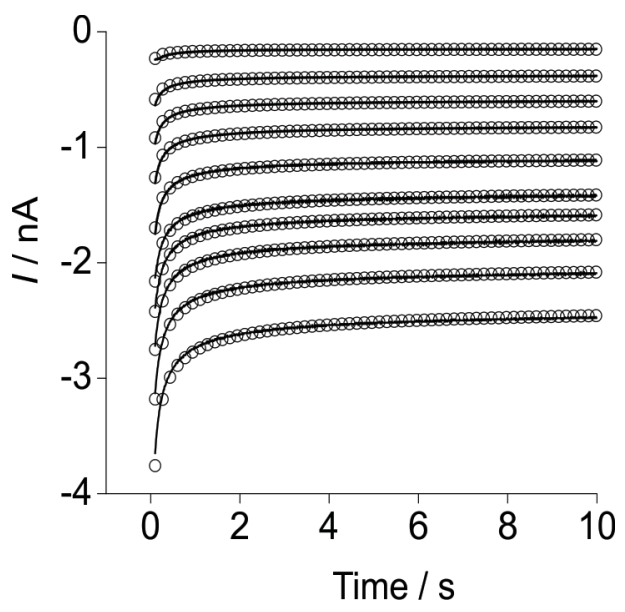

Figure 4: Chronoamperometric transients for the reduction of ten different concentrations of chlorine gas (174-3333 ppm) in the RTIL $\left[\mathrm{C}_{2} \mathrm{mim}\right]\left[\mathrm{NTf}_{2}\right]$. The potential was stepped from $1.6 \mathrm{~V}$ to $-0.1 \mathrm{~V}$. Experimental (-) and fitted (using $2.6 \times 10^{-10} \mathrm{~m}^{2} \mathrm{~s}^{-1}$ as $D$ ) theoretical (o) data following the Shoup and Szabo expression. ${ }^{18}$ 


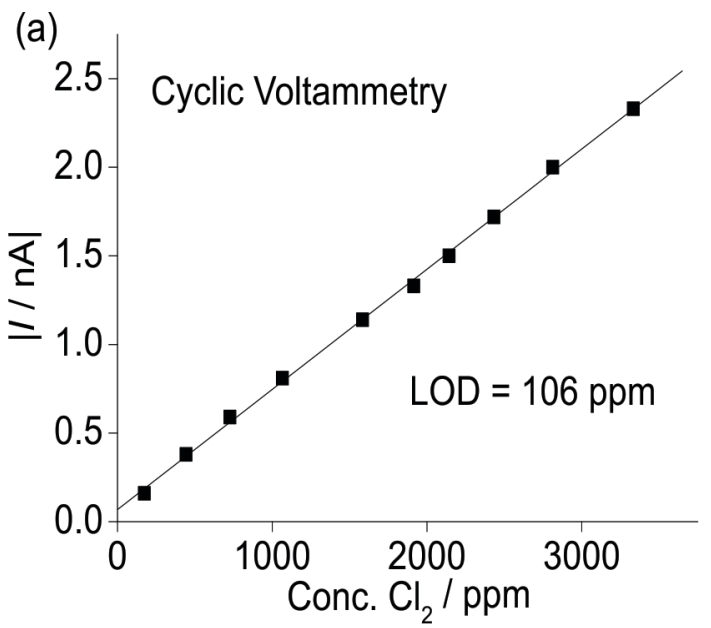

(b)

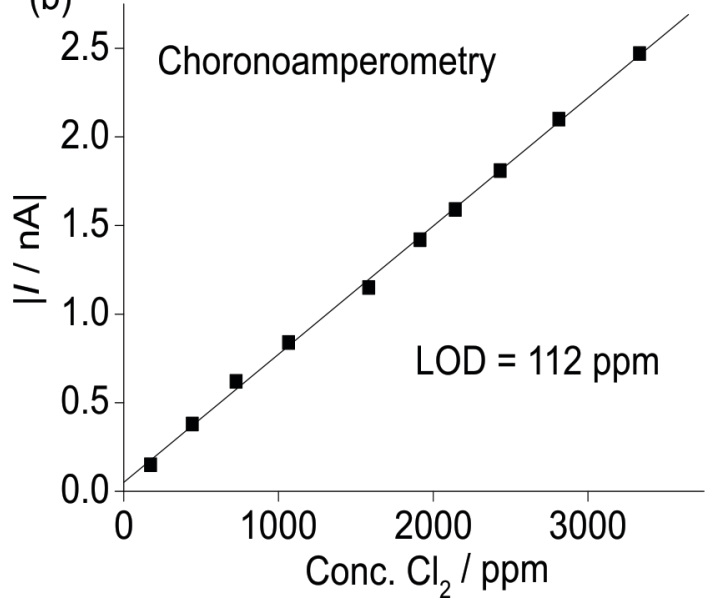

Figure 5: Calibration plots (current vs concentration) for the reduction of chlorine gas (174 -3333 ppm) obtained from the a) $\mathrm{CV}$ and b) chronoamperometric method.

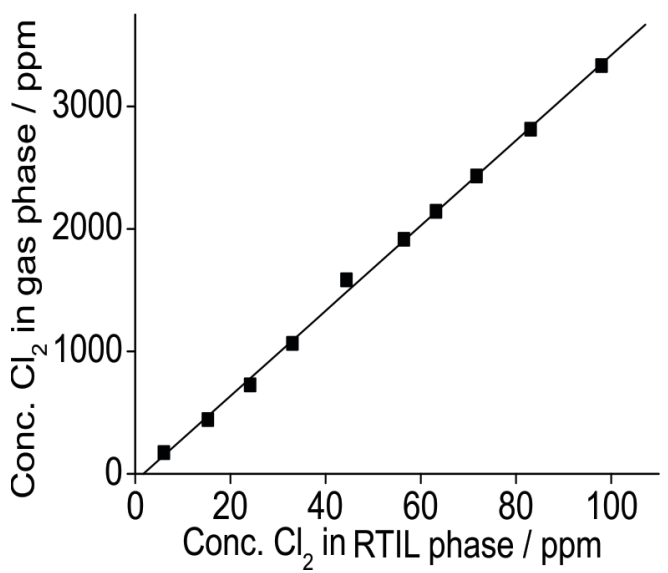

Figure 6: A plot of the concentration of chlorine in the gas phase (ppm) vs the RTIL phase (ppm). Concentrations in the RTIL phase were obtained from fitting chronoamperometric transients in Figure 4 to the Shoup and Szabo expression. ${ }^{18}$ 

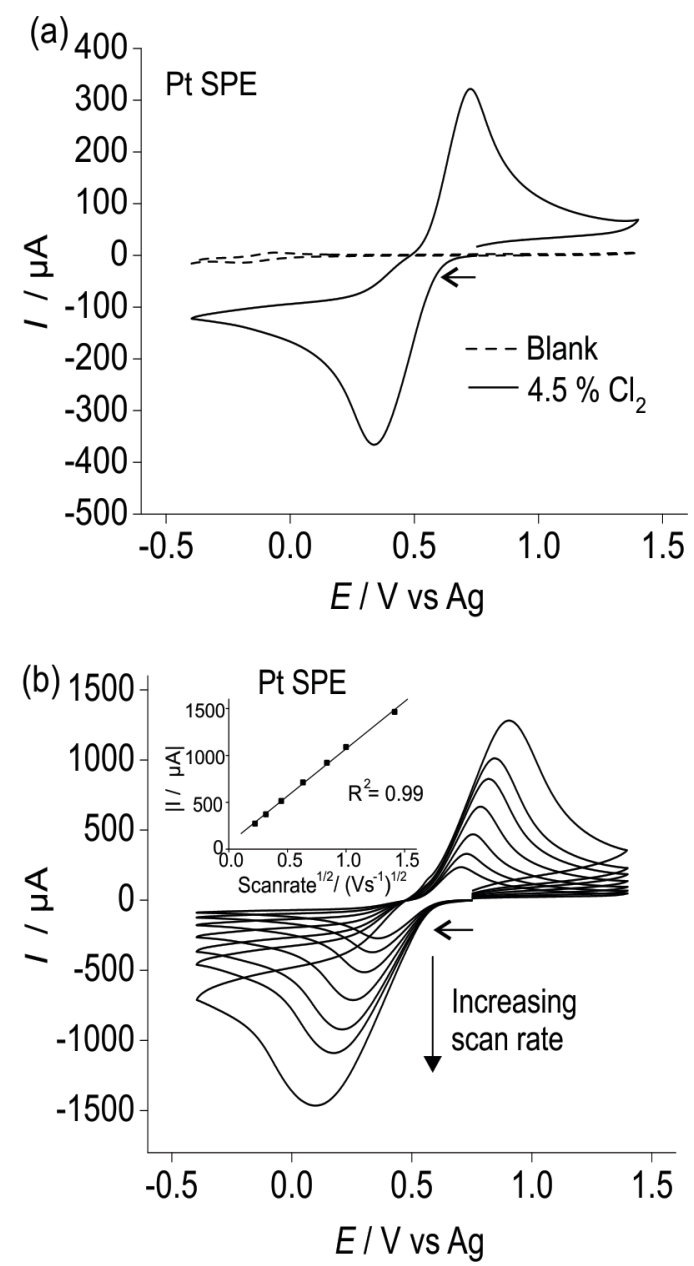

Figure 7: $\mathrm{CV}$ for the reduction of $4.5 \%$ chlorine gas (nitrogen fill) on a Pt SPE in $\left[\mathrm{C}_{2} \mathrm{mim}\right]\left[\mathrm{NTf}_{2}\right]$ a) at a scan rate of $0.1 \mathrm{~V} / \mathrm{s}$ and b) at varying scan rates between 0.05-3 V/s. Dotted line is the response in the absence of chlorine. The inset in $b$ shows the plot of square root of scan rate vs current. 

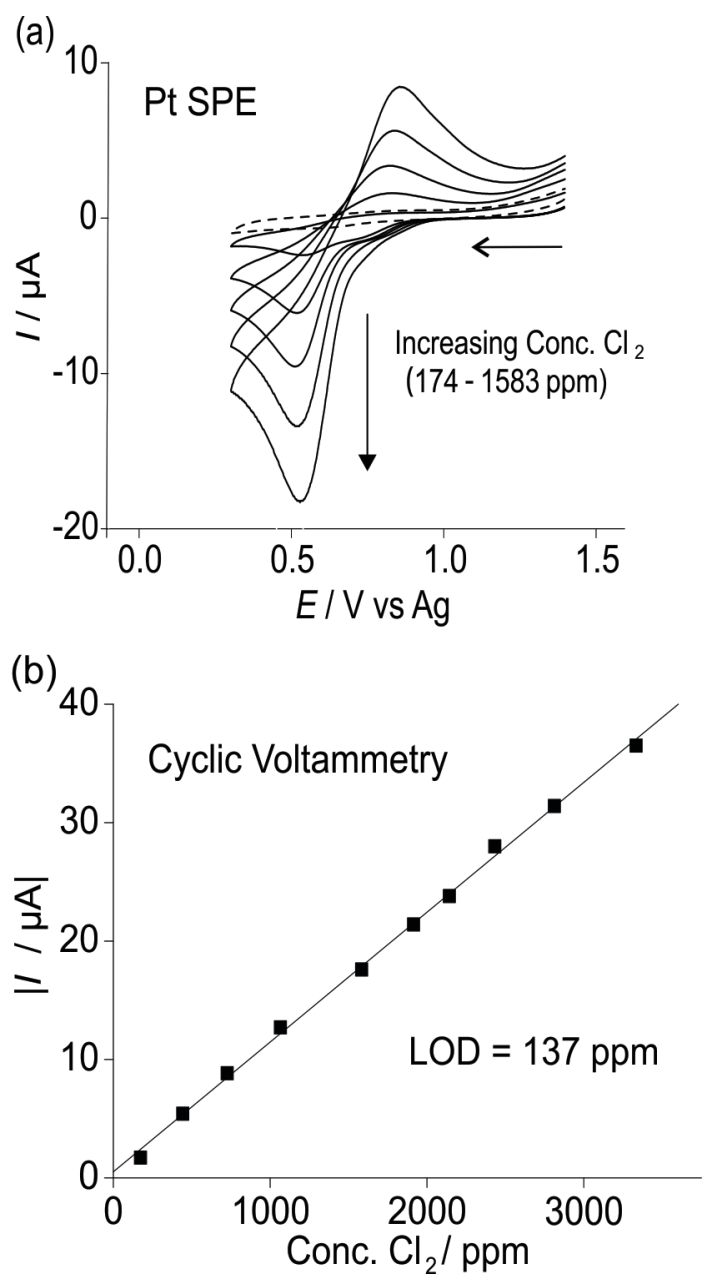

Figure 8: a) CVs for the reduction of chlorine gas (174-1583 ppm) on a Pt SPE in $\left[\mathrm{C}_{2} \mathrm{mim}\right]\left[\mathrm{NTf}_{2}\right]$ at a scan rate of $0.1 \mathrm{~V} / \mathrm{s}$. Dashed line is the response in the absence of chlorine. b) Calibration plot obtained for the reduction of chlorine gas (174-3333 ppm) using the limiting/peak current from $\mathrm{CV}$ on a $\mathrm{Pt}$ SPE. 